\title{
It is raining mice and voles: which weather conditions influence the activity of Apodemus flavicollis and Myodes glareolus?
}

\author{
Aleksandra Wróbel • Michał Bogdziewicz
}

Received: 12 November 2014 /Revised: 17 December 2014 / Accepted: 21 December 2014 / Published online: 8 January 2015

(C) The Author(s) 2015. This article is published with open access at Springerlink.com

\begin{abstract}
Rodents constitute a crucial part of food chains in many ecosystems; thus, changes in their activity might influence many other species in the community. Moreover, daily variations in activity appear to be an important adaptation, helping rodents to cope with fluctuating intensity of predation pressure and food availability. We investigated how the nightly activity of the yellow-necked mouse (Apodemus flavicollis) and the bank vole (Myodes glareolus) changes with weather conditions. Increased cloud cover enhanced activity of mice, but this effect tended to be weaker during the full moon. In turn, the activity of bank voles was positively influenced by moon phase regardless of cloud cover. Temperature had a negative effect on the activity of both species. Rainfall positively influenced A. flavicollis capture numbers, but tended to decrease the activity of M. glareolus. Therefore, while the activity of both mice and voles was under a strong influence of weather variables, their responses to weather were largely species specific.
\end{abstract}

Keywords Apodemus flavicollis $\cdot$ Daily activity $\cdot$ Myodes glareolus $\cdot$ Rodent activity $\cdot$ Small mammals $\cdot$ Weather conditions

\section{Introduction}

Weather conditions strongly affect animal activity (Vickery and Bider 1981; Pucek et al. 1993; LaHaye et al. 2004).

Communicated by P. Acevedo

A. Wróbel $(\bowtie) \cdot$ M. Bogdziewicz

Faculty of Biology, Institute of Environmental Biology, Department of Systematic Zoology, Adam Mickiewicz University, Umultowska 89, 61-614 Poznań, Poland

e-mail: wrobel_a1@wp.pl

M. Bogdziewicz

e-mail: michalbogdziewicz@gmail.com
Therefore, exploration of the relationship between animal behavior and weather is essential for a reliable description of population parameters (Cresswell et al. 1999; Orrock et al. 2004; Díaz et al. 2010; Upham and Hafner 2013; Vignoli and Luiselli 2013). Rodents are expected to be particularly sensitive to changes in weather conditions for several reasons. Their small body size and high body surface-to-volume ratio makes them vulnerable to heat loss when weather conditions are disadvantageous and results in high metabolic rates (Schmidt-Nielsen 1975). Furthermore, rodents are preyed on by many predators; thus, they strive to minimize predation risk behaviorally, by exhibiting considerable plasticity of daily activity patterns in relation to signals indicating such risk. These signals include clues provided by weather conditions (Orrock et al. 2004; Upham and Hafner 2013). Consequently, small mammals must constantly balance foraging and avoiding factors that increase mortality, including disadvantageous weather conditions. They can modify foraging patterns, intensity of intraspecific interactions, and overall daily activity when the weather changes (Stokes et al. 2001). Variation in rodent activity may strongly affect other species, e.g., their predators (Lindström and Hörnfeldt 1994; LaHaye et al. 2004; Sábato et al. 2006) or prey (Vander Wall et al. 2005; Perea et al. 2011). Understanding behavioral patterns of rodents can help explaining changes in activity of other species in the community.

Yellow-necked mouse (Apodemus flavicollis) and bank vole (Myodes glareolus) are among the most numerous rodent species in Eastern Europe (Niedzialkowska et al. 2010). Nevertheless, the influence of weather conditions on their daily activity is not well described. Many studies have focused on species of rodents living in other regions, e.g., sigmodontines in Brazil (Maestri and Marinho 2014), mice (Peromyscus sp.) (Vickery and Bider 1981) and voles (Myodes sp.) in North America (Vickery and Bider 1981; Maguire 1999), and the wood mouse (Apodemus sylvaticus) in Europe (Plesner Jensen 
and Honess 1995). Studies conducted on the yellow-necked mouse and the bank vole are presented in seasonal perspective, not in perspective of daily activity (Pucek et al. 1993; Gosálbez and Castién 1995; Marsh and Harris 2000). Mice (Apodemus sp.) and bank voles usually differ in activity attributes, e.g., chronotypes (Greenwood 1978), and thus, possibly, in predation vulnerability as well (Hansson 1987). Since these species are sympatric and have common predators, minimizing the predation risk by one of them may affect mortality of another (Sundell et al. 2003).

In the present study, we investigated how the nightly activity of both the yellow-necked mouse and the bank vole changes depending on temperature, precipitation, cloud cover, and moon phase. We hypothesized that these rodent species would optimize their behavior in order to maximize energy gains and minimize predation risk in accordance with weather alternations.

\section{Methods}

\section{Small mammal trapping}

We established eight study plots in managed European beech (Fagus sylvatica) stands in Gorzowska Forest, western Poland, located $0.2-2 \mathrm{~km}$ from one another. We conducted four monthly trapping sessions in June-September each year of the study (2010-2012). On each study plot, we established a small mammal trapping grid $(8 \times 8)$ with 64 live-traps spaced $10 \mathrm{~m}$ from each other. Plots were divided into two sets of four, and on each set, trapping was conducted simultaneously for 5 days. Traps were baited and checked at $\sim 08: 00$ and $\sim 19: 00$. Animals were assigned to species and individually marked with a uniquely numbered ear tags. During the course of this study, we live-trapped small mammals for 23,040 trap-nights.

\section{Meteorological data}

Meteorological data was obtained from Polish Institute of Meteorology and Water Management for a meteorological station in Gorzów Wielkopolski located $12 \mathrm{~km}$ from the study site. The data included hourly values of cloudiness, which ranged from 0 (no cloud cover) to 8 (complete overcast), as well as temperature $\left({ }^{\circ} \mathrm{C}\right)$, and average daily values of precipitation $(\mathrm{mm})$. The moon phase for each day of trapping was determined according to the lunar calendar on the website of Moon Information Resource And Guide (http://www. moonconnection.com/).

\section{Data analysis}

We analyzed the probability of capture by dividing traps in each night of trapping into those with (1) and without (0) captures of the focal species (the yellow-necked mouse or the bank vole). The probability of capture was successfully used in many previous studies as an indicator of activity of small and cryptic mammal species (e.g. Maguire 1999; Stokes et al. 2001; Upham and Hafner 2013). The analyses were conducted in R using GLMMs fitted by maximum likelihood with Laplace Approximation and logit link function implemented via "lme4" package (Bates et al. 2011, R Development Core Team 2013). We conducted a separate analysis for each species. In both analyses, the trapping site was included as random effect. Fixed effects included maximum cloudiness during last night (as an indicator of cloud cover), minimum temperature, precipitation (the average rainfall), phase of the moon (1 - new moon, 2 - quarter, 3 - full moon), and the interaction term between cloudiness and moonlight. We added abundance (minimum number known alive (MNKA)) of focal species on the trapping site, year, and month as covariates. We checked for collinearity between variables using variance inflation factor (VIF) from “AED” package (Zuur et al. 2009). All VIF values were less than two, which indicates no collinearity among covariates (Zuur et al. 2009). We standardized the input variables to facilitate the interpretation of the results: this procedure allows direct comparisons of effect sizes of different predictors (Schielzeth 2010).

\section{Results}

\section{Rodent species}

We caught 1638 individuals in 2010, 235 in 2011, and 1275 in 2012. Most often captured rodent species were A. flavicollis (63-72\% of all individuals during all years of the study) and M. glareolus (22-30\%). Other rodent species included the striped field mouse (Apodemus agrarius), the harvest mouse (Micromys minutus), and voles Microtus sp., but their low numbers of captures precluded further analyses.

Influence of weather on rodent captures

Increased cloud cover enhanced activity of yellow-necked mice (cloudiness effect in Table 1). Nevertheless, this effect tended to be weaker during the full moon (marginally significant negative cloudiness $\times$ moon interaction in Table 1 ). The activity of voles but not mice was positively influenced by moon phase regardless of cloud cover. Temperature had a negative effect on both mouse and vole activity. Rainfall positively influenced A. flavicollis capture numbers (Table 1), but tended to diminish the activity of M. glareolus. Capture probability of both species differed between years and months and was influenced by abundance of these rodents (A. flavicollis: year $\chi^{2}=239.42$, $\mathrm{df}=2, p<0.0001$, month $\chi^{2}=100.60, \mathrm{df}=3, p<0.0001$, 
Table 1 The influence of weather variables on the capture probability of yellow-necked mouse and bank vole. Input variables were standardized to allow direct comparisons of effect sizes of particular predictors

\begin{tabular}{|c|c|c|c|c|c|c|}
\hline \multirow[t]{2}{*}{ Weather variable } & \multicolumn{3}{|l|}{ A. flavicollis } & \multicolumn{3}{|l|}{ M. glareolus } \\
\hline & Regression coefficient $( \pm \mathrm{SE})$ & $Z$ & $P$ & Regression coefficient $( \pm \mathrm{SE})$ & $Z$ & $P$ \\
\hline Cloudiness & $0.09( \pm 0.02)$ & 4.74 & $<0.0001$ & $0.05( \pm 0.03)$ & 1.60 & 0.11 \\
\hline Moon phase & $0.03( \pm 0.02)$ & 1.54 & 0.12 & $0.22( \pm 0.04)$ & 5.23 & $<0.0001$ \\
\hline Temperature & $-0.15( \pm 0.02)$ & -6.01 & $<0.0001$ & $-0.09( \pm 0.03)$ & -2.82 & 0.005 \\
\hline Rainfall & $0.06( \pm 0.02)$ & 3.09 & 0.002 & $-0.07( \pm 0.04)$ & -1.73 & 0.08 \\
\hline Cloudiness $\times$ moon phase interaction & $-0.04( \pm 0.02)$ & -1.77 & 0.08 & $-0.004( \pm 0.03)$ & -0.12 & 0.91 \\
\hline
\end{tabular}

abundance $\chi^{2}=598.18, \mathrm{df}=1, p<0.0001 ;$ M. glareolus: year $\chi^{2}=58.87, \mathrm{df}=2, p<0.0001$, month $\chi^{2}=93.47, \mathrm{df}=3$, $p<0.0001$, abundance $\chi^{2},=105.78, \mathrm{df}=1, p<0.0001$ )

\section{Discussion}

Our study demonstrates that both yellow-necked mouse and bank vole optimize their behavior due to weather alternations. These changes in activity may be explained by aiming to maximize energy gains and minimize predation risk.

An increase in the ambient temperature had a negative effect on both mouse and vole activity. This impact has often been observed in other rodent species in the temperate climate zone (Vickery and Bider 1981; Orrock and Danielson 2009). When the difference between ambient and body temperature increases, the metabolic rate is raised as well to compensate for heat loss (Vickery and Bider 1981). Thus, low temperatures force rodents to forage more intensively because a higher intake of calories is needed to maintain the appropriate body temperature.

A. flavicollis showed higher capture rates during rainfall. One previous study revealed that the activity of both the yellow-necked mouse and the wood mouse increased during warm, cloudy nights, especially in the presence of light rain (Marten 1973). Some researchers suggest that rain helps to mask the sound of movements and the odors emitted by rodents (Vickery and Bider 1981; Brown et al. 1988). Moreover, mammalian predators, e.g., weasels, may reduce activity in rainy conditions to avoid the thermoregulatory cost of a wet coat combined with cool temperatures (Brandt and Lambin 2005).

Overcast contributed to a higher number of mouse, but not vole captures. Cloud cover appears to be an important indirect clue for rodents, which allows to estimate the potential predation risk better than direct clues, such as urine (scent) of predators (Orrock et al. 2004). In contrast to scent, cloud cover confers information on different danger types, i.e., various types of predators that rely on vision when hunting, not on one specific species (Orrock et al. 2004; Orrock and Danielson 2009).
Vole capture rates significantly increased with moonlight, but such an effect did not occur for mice. Moreover, this effect was reduced by increasing overcast. A number of studies described the negative effect of the moon on the nightly activity of rodents (Lima and Dill 1990; Zollner and Lima 1999; Orrock et al. 2004; Upham and Hafner 2013). Consistent with the predation risk hypothesis, the moonlight is an important clue with respect to predation: the stronger the moonlight, the higher risk of being predated (Lima and Dill 1990; Upham and Hafner 2013; Prugh and Golden 2014). Nevertheless, it has also been shown that the activity of many prey species, including small mammals, may increase with moonlight (Bouskila 1995; Zollner and Lima 1999; Maestri and Marinho 2014; Prugh and Golden 2014). According to the visual acuity hypothesis, moonlight improves not only the vision of the predator, but of the prey as well. During the full moon, the prey is able to detect predators and/or forage more efficiently (Bouskila 1995; Prugh and Golden 2014). This phenomenon may explain the increased activity of bank voles in our study. However, the responses to moonlight might be mediated by vegetation structure (Díaz 1992), making interpretation of its effects more challenging.

Precipitation may reduce prey detectability as well as decrease small mammal activity, which negatively influences reproduction and survival of species preying on rodents, such as owls (Vickery and Bider 1981; LaHaye et al. 2004) and mammalian predators (Sábato et al. 2006). Thus, weather conditions may indirectly influence the hunting effectiveness of predators, highly limiting their populations, especially during breeding season.

In conclusion, weather conditions influenced behavior of A. flavicollis and M. glareolus, but the reaction to weather was not the same in these two species. Daily changes in activity appear to be an important adaptation, helping rodents to cope with variation in predation pressure and food availability (Díaz et al. 2010), both of which might be influenced by weather. Small mammals have to maintain the trade-off between predation risk, foraging, and dispersion (Zollner and Lima 1999), and this balance appears to be affected by weather. Causes of the interspecific differences in small mammal 
responses to weather conditions could provide an interesting subject for further studies.

Acknowledgments We thank Rafał Zwolak for comments on the first versions of this manuscript and Polish Institute of Meteorology and Water Management for providing meteorological data. Special thanks to Sylwia Dziemian-Zwolak, Milena Zduniak, and many other students for invaluable help during the field work and Ryszard Zwolak for field vehicle maintenance. The study was supported by Polish Ministry of Science and Higher Education Grant NN304391537, and MB was supported by Adam Mickiewicz Foundation Scholarship.

Ethical approval All capture and handling methods were approved by the Local Ethical Commission for Experiments with Animals in Poznań (permits no. 62/2008 and 13/2012)

Conflict of interest The authors declare that they have no conflict of interest.

Open Access This article is distributed under the terms of the Creative Commons Attribution License which permits any use, distribution, and reproduction in any medium, provided the original author(s) and the source are credited.

\section{References}

Bates D, Maechler M, Bolker B (2011) lme4: linear mixed-effects models using S4 classes. R package version 0.999375-38. http:/CRAN.Rproject.org/package $=$ lme 4

Bouskila A (1995) Interactions between predation risk and competition: a field study of kangaroo rats and snakes. Ecology: 165-178

Brandt MJ, Lambin X (2005) Summertime activity patterns of common weasels Mustela nivalis vulgaris under differing prey abundances in grassland habitats. Acta Theriol 50(1):67-79

Brown JS, Kotler BP, Smith RJ, Wirtz WO (1988) The effects of owl predation on the foraging behaviour of heteromyid rodents. Oecologia 76:408-415

Cresswell W, Ruxton GD, Hilton GM (1999) Choice of foraging area with respect to predation risk in redshanks: the effects of weather and predator activity. Oikos 87(2):295-302

Díaz M (1992) Rodent seed predation in cereal crop areas of Central Spain: effects of physiognomy, food availability, and predation risk. Ecography 15:77-85

Díaz M, Torre I, Arrizabalaga A (2010) Relative roles of density and rainfall on the short-term regulation of Mediterranean wood mouse Apodemus sylvaticus populations. Acta Theriol 55:251-260

Gosálbez J, Castién E (1995) Reproductive cycle, abundance and population structure of Apodemus flavicollis (Melchior, 1834) in the western Pyrenees. Mammalia 59:385-396

Greenwood PJ (1978) Timing of activity of the bank vole Clethrionomys glareolus and the wood mouse Apodemus sylvaticus in a deciduous woodland. Oikos: $123-127$

Hansson L (1987) An interpretation of rodent dynamics as due to trophic interactions. Oikos:308-318

LaHaye WS, Zimmerman GS, Gutiérrez RJ (2004) Temporal variation in the vital rates of an insular population of spotted owls (Strix occidentalis occidentalis): contrasting effects of weather. Auk 121(4):1056-1069

Lima SL, Dill M (1990) Behavioral decisions made under the risk of predation: a review and prospectus. Can J Zool 68:619-640
Lindström ER, Hörnfeldt B (1994) Vole cycles, snow depth and fox predation. Oikos:156-160

Maguire CC (1999) Rainfall, ambient temperature, and Clethrionomys californicus capture frequency. Mammal Rev 29(2):135-142

Marsh A, Harris S (2000) Partitioning of woodland habitat resources by two sympatric species of Apodemus: lessons for the conservation of the yellow-necked mouse (A. flavicollis) in Britain. Biol Conserv 92: $275-283$

Marten G (1973) Time patterns of Peromyscus activity and their correlations with weather. J Mammal:169-188

Maestri R, Marinho JR (2014) Singing in the rain. Rainfall and moonlight affect daily activity patterns of rodents in a Neotropical forest. Acta Theriol:1-7

Niedzialkowska M, Konczak J, Czarnomska S, Jedrzejewska B (2010) Species diversity and abundance of small mammals in relation to forest productivity in northeast Poland. Ecoscience 17:109-119

Orrock JL, Danielson BJ (2009) Temperature and cloud cover, but not predator urine, affect winter foraging of mice. Ethology 115(7):641648

Orrock JL, Danielson BJ, Brinkerhoff RJ (2004) Rodent foraging is affected by indirect, but not by direct, cues of predation risk. Behav Ecol 15:433-437

Perea R, Miguel AS, Gil L (2011) Acorn dispersal by rodents: the importance of re-dispersal and distance to shelter. Basic Appl Ecol 12: $432-439$

Plesner Jensen S, Honess P (1995) The influence of moonlight on vegetation height preference and trappability of small mammals. Mammalia 59:35-42

Prugh LR, Golden CD (2014) Does moonlight increase predation risk? Meta-analysis reveals divergent responses of nocturnal mammals to lunar cycles. J Anim Ecol 83(2):504-514

Pucek Z, Jedrzejewski W, Jedrzejewska B, Pucek M (1993) Rodent population dynamics in a primeval deciduous forest (Bialowieza National Park) in relation to weather, seed crop, and predation. Acta Theriol 38:199-199

R Development Core Team (2013) R: a language and environment for statistical computing. R Foundation for Statistical Computing, Vienna, Austria

Schielzeth H (2010) Simple means to improve the interpretability of regression coefficients. Methods Ecol Evol 1:103-113

Schmidt-Nielsen K (1975) Scaling in biology: the consequences of size. J Exp Zool 194:287-307

Stokes MK, Slade NA, Blair SM (2001) Influences of weather and moonlight on activity patterns of small mammals: a biogeographical perspective. Can J Zool 79:966-972

Sundell J, Eccard JA, Tiilikainen R, Ylönen H (2003) Predation rate, prey preference and predator switching: experiments on voles and weasels. Oikos 101(3):615-623

Sábato MAL, Melo LFBD, Magni EMV, Young RJ, Coelho CM (2006) A note on the effect of the full moon on the activity of wild maned wolves, Chrysocyon brachyurus. Behav Process 73:228-230

Upham NS, Hafner JC (2013) Do nocturnal rodents in the Great Basin Desert avoid moonlight? J Mammal 94:59-72

Vander Wall SB, Kuhn KM, Beck MJ (2005) Seed removal, seed predation, and secondary dispersal. Ecology 86:801-806

Vickery W, Bider J (1981) The influence of weather on rodent activity. J Mammal:140-145

Vignoli L, Luiselli L (2013) Better in the dark: two Mediterranean amphibians synchronize reproduction with moonlit nights. Web Ecol 13:1-11

Zollner PA, Lima SL (1999) Illumination and the perception of remote habitat patches by white-footed mice. Anim Behav 58(3):489-500

Zuur A, Ieno EN, Walker N, Saveliev AA, Smith GM (2009) Mixed effects models and extensions in ecology with R. Springer 